\section{Commentary: Recurrent xenopericardial elephant trunk graft infection: Snatching victory from the jaws of defeat}

\author{
Rachel Eikelboom, MD, a,b \\ Roberto Vanin Pinto Ribeiro, MD, ${ }^{c}$ \\ Rashmi Nedadur, MD, ${ }^{\mathrm{c}}$ and \\ Bobby Yanagawa, $\mathrm{MD}, \mathrm{PhD}^{\mathrm{c}}$
}

In this edition of the Journal, Minegishi and colleagues ${ }^{1}$ present a patient who underwent total arch replacement with elephant trunk for type A dissection. She developed an Enterobacter cloacae graft infection and underwent redo total arch replacement with xenopericardial roll graft. She then developed fungal infection of the elephant trunk with a near-occlusive vegetation and had redo-redodescending aortic replacement via left chest. To our knowledge, this is the first report of a massive vegetation on an elephant trunk as a cause of near occlusion. That this surgical team successfully performed 3 high-risk operations is a tour de force and a tribute to the resilience of the surgical team and indeed the patient.

Thoracic aortic prosthetic graft infection has an incidence of less than $3 \%$ but is associated with $25 \%$ to $75 \%$ mortality. ${ }^{2}$ There is limited evidence to guide management, although some strategies include a combination of (1) reoperation with aggressive debridement and aortic replacement with a rifampin-soaked Dacron graft, homograft, or xenopericardial graft; (2) coverage with native tissue (eg,

\footnotetext{
From the ${ }^{\mathrm{a}}$ Department of Surgery, Max Rady College of Medicine, University of Manitoba, Winnipeg, Manitoba; ${ }^{b}$ Division of Cardiac Surgery, McMaster University, Hamilton, Ontario; and ' Division of Cardiac Surgery, St Michael's Hospital, University of Toronto, Toronto, Ontario, Canada.

Disclosures: The authors reported no conflicts of interest.

The Journal policy requires editors and reviewers to disclose conflicts of interest and to decline handling or reviewing manuscripts for which they may have a conflict of interest. The editors and reviewers of this article have no conflicts of interest.

Received for publication Dec 2, 2020; revisions received Dec 2, 2020; accepted for publication Dec 15, 2020; available ahead of print Dec 28, 2020.

Address for reprints: Bobby Yanagawa, MD, PhD, Division of Cardiac Surgery, St Michael's Hospital, 30 Bond St, 8th Floor, Bond Wing, Toronto, Ontario M5B 1W8, Canada (E-mail: yanagawab@smh.ca).

JTCVS Techniques 2021;6:52-3

2666-2507

Copyright $(2020$ The Authors. Published by Elsevier Inc. on behalf of The American Association for Thoracic Surgery. This is an open access article under the CC BY-NCND license (http://creativecommons.org/licenses/by-nc-nd/4.0/).

https://doi.org/10.1016/j.xjtc.2020.12.027
}

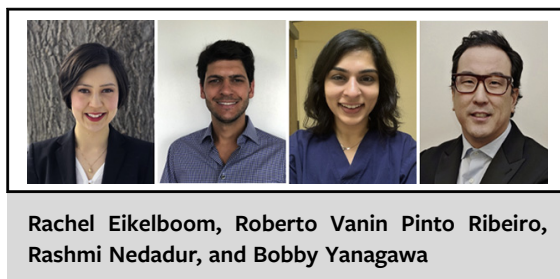

CENTRAL MESSAGE

Large vegetation of a xenoperi-

cardial elephant trunk graft is an

unusual cause of aortic

obstruction.

omental) flap; (3) local antibiotic infusion; (4) life-long suppressive antibiotics; and (5) wound drainage with or without negative-pressure dressings. ${ }^{3}$ Familiarity with the range of therapeutic options, and flexibility in modifying the plan in the face of unanticipated challenges, is key.

In the absence of robust evidence, guidelines for similar conditions can be instructive. The American Heart Association recommends that patients with fungal endocarditis receive parenteral antifungal therapy with amphotericin $\mathrm{B}$ plus an additional antifungal agent for a minimum of 6 weeks, followed by consideration of lifelong oral azole therapy. ${ }^{4}$ Guidelines for intra-abdominal graft infections suggest the use of biologic over prosthetic material. They suggest use of arterial allografts over venous autografts due to the morbidity associated with vein harvest and wound healing, and suggest the use of rifampin- or silversoaked synthetic grafts. ${ }^{3,5}$ The basic principle of all infected prosthetic materials is source control with removal of all infected tissue and aggressive debridement. As always, a multidisciplinary team is recommended to include vascular and cardiothoracic surgeons, cardiologists, infectious diseases specialists, and radiologists, so that where evidence is lacking, clinical decision-making can benefit from broad expertise and collaboration.

We thank the authors for sharing this rare presentation of graft occlusion by massive vegetation, and we congratulate the authors on their heroic and innovative surgical strategy which is instructive for those encountering similar challenging scenarios.

\section{References}

1. Minegishi S, Inaba Y, Endo H, Kubota H. A large vegetation on a xenopericardial roll elephant trunk graft. J Thorac Cardiovasc Surg Tech. 2021;6:46-9.

2. Tossios P, Karatzopoulos A, Tsagakis K, Sapalidis K, Grosomanidis V, Kalogera A, et al. Treatment of infected thoracic aortic prosthetic grafts with the in situ preservation strategy: a review of its history, surgical technique, and results. Heart Lung Circ. 2014;23:24-31. 
3. O'Connor S, Andrew P, Batt M, Becquemin JP. A systematic review and metaanalysis of treatments for aortic graft infection. J Vasc Surg. 2006;44:38-45.

4. Baddour LM, Wilson WR, Bayer AS, Fowler VG Jr, Tleyjeh IM, Rybak MJ, et al. Infective endocarditis in adults: diagnosis, antimicrobial therapy, and management of complications: a scientific statement for healthcare professionals from the American Heart Association. Circulation. 2015;132 1435-86.

5. Wilson WR, Bower TC, Creager MA, Amin-Hanjani S, O'Gara PT, Lockhart PB, et al Vascular graft infections, mycotic aneurysms, and endovascular infections: a scientific statement from the American Heart Association. Circulation. 2016;134:e412-60. 